\title{
Climate change perceptions and preparation in the United States territories in the Pacific: American Samoa, Guam, and the Commonwealth of the Northern Mariana Islands
}

\author{
Michael B. Schwebel \\ Department of Geography and Urban Studies, Temple University, USA \\ I00 Resilient Cities (I00RC) a Rockefeller Foundation Sponsored Project, USA \\ michael.schwebel@temple.edu
}

\begin{abstract}
The association between and among climate change, preparation, and perceptions on islands is becoming more commonplace-but what about on extraterritorial land governed from thousands of miles away? This article consists of on-the-ground fieldwork and interviews speaking with decision-makers and leadership personnel in American Samoa, Guam, and the Commonwealth of the Northern Mariana Islands on the following topics: how climate change is addressed, what the general attitude on-island is towards climate change, if islands' proximities to independent countries affect the territories' preparation, and if being a part of the United States is considered an asset in planning for climate change. The results from the study show that up until very recently, climate change was not readily discussed, and, when it had been, it was often only discussed with concern for ocean life. Additionally, respondents lamented that often their non-US neighbours were able to better prepare, but US territories were either outright excluded due to their tertiary sovereignties or due to lack of representation from the Federal Government at meetings. Research herein illustrates that being a territory of the United States was considered an asset in many respects due to the hypothetical protection and funding available in the event of major disaster. An emerging theme from the study is that the American territories in the Pacific sit within the margins and periphery of climate-change planning within the United States and are behind many of their neighbours in both their perceptions and preparation efforts of the effects of a changing climate.
\end{abstract}

Keywords: American Samoa, climate change, Commonwealth of the Northern Mariana Islands, governance, Guam, Pacific, territories

$\underline{\text { https://doi.org/10.24043/isj. } 57}$

C 2018 - Institute of Island Studies, University of Prince Edward Island, Canada.

\section{Introduction}

Due to the precariousness of climate change, islands and islanders have captured the world's interest, most recently due to recent extreme cyclonic events in the Caribbean affecting both sovereign nations and territories. Unlike the immediate shock and destruction of a hurricane, it is the underlying long-term stresses-such as saltwater intrusion to the freshwater lens-that have more often led islanders to relocate due to the loss of arable land, increased nuisance flooding, and other severe events (Tompkins et al., 2005, p. 20).

A dilemma islanders face is the gridlock-based inability to adapt to the current and forecasted effects of climate change because of certain political boundaries-also recently evidenced in places such as Puerto Rico and the Virgin Islands (Selter, 2015). Because no prior research has analyzed or attempted to understand how the United States Territories in the Pacific have anticipated, planned for, or seek to handle the current and forecasted effects 
of climate change, this article endeavours to obtain these responses directly from the islanders making and being affected by these decisions-or the lack thereof.

Within island states around the world, including those within a territorial type of governance and arrangement, a dearth of intra-country and inter-country transportation, limited wealth, visa and employment issues, and limits to free movement quash a potential stressor-release to climate change (Bedford, 2008, p. 5; Ware, 2005, p. 236). In addition, the lack of robust international standards addressing climate change can stop cooperation at these boundaries; therefore, if a consensus can be reached, who stands to gain from adaptation and mitigation (Page, 2008, p. 556)? These questions surrounding the impetuses of decisionmaking and agreements prove valid in the forthcoming research as islands describe their relationships and abilities to interact with one another across the Pacific.

\section{Problem statement}

Many of the previous Pacific Small Island States' (PSIS) studies have focused on independent islands' climate-change forecasts, imminent exposure to climate-change effects, and the lack of political and related resources for coping with those effects (Betzold, 2010; Docherty \& Giannini, 2009; Jacobs, 2005; Robinson, 2015; Schofield, 2009; Weir \& Pittock, 2017). Additionally, studies have shown that island assessments often ignore other developmentrelated issues on islands with the blame inadvertently shifting to a catch-all climate-change category, when, in fact, other social and infrastructural challenges abound and need to be addressed (Kelman, 2014). Similarly, even when climate change is analyzed with regard to related challenges, the extraterritorial lands of countries-whether they be nearby or halfway across the globe-are often left to the margins of these analyses (Schwebel, 2018a).

This study examined an understudied subset of PSIS quite overlooked when discussing resiliency, specifically how United States Territories in the Pacific self-identify with respect to climate-change planning: American Samoa, Guam, and the Commonwealth of the Northern Mariana Islands (CNMI). It should be noted that American Samoa and Guam are territories of the United States, although with differing forms of government and territorial arrangements with the United States. The Commonwealth of the Northern Mariana Islands (CNMI) is a commonwealth of the United States and is not formally a territory. However, since all three island groupings are technically referred to as United States Overseas Territories, for the purposes of this paper the term 'territories' will be used to refer collectively to American Samoa, Guam, and CNMI.

\section{Context and literature}

Francois Taglioni (2011, p. 45) explored the concept of insularity and how island states are smaller types of spaces that grapple with or excel at the notion of being somewhat removed from the world. The ways in which the islands in the study-American Samoa, Guam, and CNMI-as American Territories are insulated from the mainland of the United States, and how the governance of those rules affect how the territories contend with issues of climate change, is pertinent to unearth. For these reasons, specific interview questions in this paper endeavour to uncover how states in a geographical region may or may not approach complex issues in a similar fashion.

Speaking to collaboration and joint environmental decision-making, the "interstate cooperation around shared interests is said to be essential if 'inherently transnational' problems are to be addressed effectively" - but do all states view the effects of climate change as truly transnational (Lipschutz \& Conca, 1993, p. 328)? Aside from intercountry differences in the creation of environmental policy, "nonstate actors [...] influence the policies of individual state actors toward global environmental issues as well as the international negotiation process" 
(Chasek et al., 2010, p. 113). In the case of the US Territories, are they, in fact, non-state actors within the United States of America? Seen below, different respondents' interview responses shed light upon differing influences and influencers that have had some effect on how decisions are made on-island.

The importance of governance as related to collaboration, negotiation, and joint environmental decision-making rests within the collaborative relationships among states, groups, or regimes. Yet, "interlinkages of parallel policies and regimes within a horizontally and vertically segmented governance system" can sometimes be the source of "divergent policies in global environmental governance" (Biermann, 2004, p. 12). The US Territories illustrate these segmented and siloed systems as the horizontal and vertical distance of the United States spans almost a dozen time zones with multilayered government systems in place.

In the mid- to late $20^{\text {th }}$ century, "regionalization was [...] considered to be the solution to the constraints imposed by smallness" within small islands (Grote, 2010, pp. 171-172). Through these types of designs, islands or other regionally collaborative states can focus on "principles that make for more successful management of common pool resources at the local level," no matter whether the resource is migrating schools of tuna, carbon emissions, or agreements on sea level and state boundaries (Bernauer, 2002, p. 10). Agreements like these sometimes can tie decision-makers' hands, keeping them from achieving more or perhaps from achieving what the decisionmaker originally sought to entertain (Ostrom, 1990, pp. 1213). For example, a hypothetical collective decision of Pacific countries to limit harvesting of bêche-de-mer could theoretically increase the population of the species by halting overfishing, but at the same time if the catch limit is still too high, it would prohibit individual countries from imposing more stringent standards since discord could ensue by breaking away from the regional pact.

Lastly, since some stakeholders and agencies are under the impression that all smallisland states are in immediate, dire need for migration and relocation of their residents, they are unintentionally giving the message that agencies, islanders, and their leaders "had effectively given up on mitigation measures to avert future impacts of climate change" and are now looking for relocation assistance (McNamara \& Gibson, 2009, p. 480). This type of reaction is related to the opinion expressed by some entities about whether it is worth investing millions of dollars in a vulnerable PSIS that is home to 10,000 people versus using funds for further-reaching projects in more populated locales.

\section{Methodology}

All research (site visits and semi-structured interviews) was conducted within the Pacific region, specifically American Samoa, Guam, and the Commonwealth of the Northern Mariana Islands (CNMI) during the period of January through April 2014. The data was transcribed between May through July 2014 and was coded by the same researcher who performed all interviews. The transcribed data were then presented to and reviewed by a research team familiar with the content. This research team did not find any concern or implicit bias presented within the coded material and associated research.

A semi-structured interview "allows the researcher to cover a specific list of topic areas" with the flexibility to follow up on and explore the answers given by the interviewee (Jarratt, 1996, p. 9). In situations with only one opportunity to interview a person, semi-structured interviewing "maintains discretion to follow leads" and is guided by a standard interview method that the researcher uses during the process (Bernard, 1988, p. 205). On each location a standard of interviewing at least 10-12 people under these aforementioned categories was implemented and achieved. Follow-up questions to those listed in Table 2 were not normally asked unless a participant began explaining a concept that was unfamiliar to the interviewer or if the interviewee returned to a topic from a prior question. 
These interviews were held with islanders who were involved with climate-change planning on the island. Initial contacts were found through a list of stakeholders in their Climate Change Action Plan (CCAP) or most appropriate document. Additional interviewees were found by asking already-interviewed islanders about additional people on island to contact. These were people who were involved in many aspects of climate-change planning or preparation, ranging from a formal position to a community leader: in other words, the snowball method. The spectrum of interviewees ranged from residents of the island to territorial and federal employees to environmental organization members, business associations, companies, and others. The ratio of men to women interviewee respondents was near equal and the age range of respondents ranged from recent college graduates through retirees. In total, as the findings from the research occurred within a qualitative and analytical environment, there are limitations as selection of the interviews, coding, analysis, and assessment are all prone to human error, although many quality assessments and checks were utilized throughout the research process to lessen any intended and non-intended biases.

Institutional Review Board (IRB) approval was received from Temple University. American Samoa and Guam both required additional IRBs to conduct human research (interviews). In total, IRB approval was received from all necessary entities.

The interviews ranged from approximately 30 to 45 minutes in length. The data were stored behind password-protected drives. Participants were told as part of oral consent that the foreseeable risks or discomforts were discussing a timely issue on which they may have a strong opinion; they were also notified that the benefit they could obtain from the research would be to contribute to the better understanding of climate-change policy in PSIS. The researcher provided participants with confidentiality by neither identifying the interviewees' name and position, nor identifying which of the American Territories the interviewees hailed from. Only the researcher had access to a list of participants' PSIS.

\section{Interview results: United States Territories in the Pacific}

\section{Data and response overview}

The goal of approximately 10-12 interviews (see Table 1) in each location was successfully reached, using a 15-question semi-structured interview format that was similar to but not identical to the questions in the article (see Schwebel, 2018b). Because of IRB protocols PSIS were given randomized identification from PSIS $_{500}$ through PSIS 999 to alleviate any concern about piecing together PSIS' identities. For example, PSIS 555 and PSIS $_{679}$ and additional identifiers could reference the same PSIS.

Table 1: Pacific Small Island States (PSIS) and number of interviews.

\begin{tabular}{lll}
\hline Pacific Small Island State & $\begin{array}{l}\text { Two-Letter } \\
\text { Abbreviation }\end{array}$ & $\begin{array}{l}\text { Number of } \\
\text { Interviews }\end{array}$ \\
\hline American Samoa & AS & 11 \\
Guam & GU & 13 \\
Commonwealth of the Northern Mariana Islands & NM & 11 \\
\hline
\end{tabular}

Quotations and analysis within this study concentrate on four of the questions-numbers 1, 2, 6, and 8-as they sought to understand perceptions of climate change in the American Territories (see Table 2). These questions were chosen in conjunction with acceptable norms with the approval of the aforementioned IRBs within a large research study that sought to understand climate-change perceptions and understanding across the Pacific Region. The specific questions chosen within this manuscript focus predominantly on the relationship between the islands and their neighbours and host countries. Moreover, the 
quotations chosen represented the major and broad sentiments expressed during the participants' answers. Although it is possible that some interviewees were either duty-bound or felt allegiance to a specific position, respondents often included comments referencing the anonymity of the interviews, enabling them to talk freely. Some respondents who worked for higher-level authorities sometimes cited their managements' official take on an issue, saying that it was the official position and sometimes countered with why they felt differently.

Table 2: Interview questions for government officials, decision-makers, project managers in American Samoa, Guam, and the Commonwealth of the Northern Mariana Islands. $\star \star$ Asterisks replaced the name of the appropriate PSIS during the interview. Questions in bold illustrate the questions from the research used within this analysis.

1. How would you describe the ways in which climate change is addressed in $(\star \star)$ ?

2. What would you say is the general attitude in $(\star \star)$ toward climate change?

3 . How would you describe ( $\star \star$ 's) climate change plans, climate change policies, and climate change projects?

4. Does $(\star \star)$ work with other PSIS in addressing climate change?

5. Do you happen to be familiar-and if so, how-with AOSIS, the Alliance of Small Island States or CROP, the Council of Regional Organizations of the Pacific?

6. Does ( $\star^{\prime}$ 's) status as a United States' territory near many other PSIS that are not part of the United States have any effect on climate change preparation in $(\star \star)$ ?

7. On a scale of $1-10$, how would you describe the degree to which $(\star \star)$ is adequately preparing for climate change, and why?

8. Although ( $\star \star ' s)$ status is not a "state" of the United States, do you think that being part of the greater network of the United States is an asset to ( $\left.{ }^{\star}\right)$ in preparing for climate change?

9. If there were an item or two that you think $(\star \star)$ is excelling at in terms of climate change preparation, what would that be?

10. Do you think any of the physiographical (geographical) or historical aspects of $(\star \star)$ affects the type of climate change plans, policies, and projects being instituted?

11. Do you think any other PSIS are in a similar situation to that of $(\star \star)$, and why?

12. How would you describe the similarity between the intended goals of climate change plans, policies, and projects, and what is actually being done in $(\star \star)$ ?

13. If there were one or two items that you could change regarding how climate change is handled in $(\star \star)$, what would it be?

14. Is there anything else in reference to the broader discussion regarding climate change in $(\star \star)$ that you would like to mention or discuss?

15. Is there any person in particular or any project site that you would suggest I contact/visit to obtain more information regarding climate change plans, projects, and policies here in $(\star \star)$ ?

Interviewees' responses

Below are the bolded four questions from Table 2, along with the three different island groupings with their responses. American Samoa, Guam, and The Commonwealth of the Northern Mariana Islands are all referred to as locations below. However, the first location in Question \#1, for example, may not be the same island grouping that is listed as first location in Question \#8. The three island groupings were randomly assigned their name as either location \#1, location \#2, or location \#3 for each of the questions to guarantee nonattribution of interviewees and to prohibit piecing together the identity of the islands and the identities of respondents. 


\section{Interviewees' responses to Question \#1}

Within the first location for Question \#1, respondents state that they "don't think necessarily addressing climate change directly is the most effective way in dealing with it" because it is such a large concept to both educate and grapple with, so "if you address something more like flooding" or food shortages, you are framing it in a way that is not using the words climate change $\left(\mathrm{PSIS}_{671}\right)$. Along those same lines another said that the "average person is [...] is sort of vaguely aware and interested and now other people have heard world sea-level's rising and they get the constant stuff from the media and what they see on sort of popular" but that it is still "not really a major concern of most people" as it does not sit on their principal radar $\left(\mathrm{PSIS}_{893}\right)$. Others were in agreement in the lack of addressing climate change due to "some of our neighbors in the region that I think to some degree are feeling much more concerned about the impacts" such as king tides where the "changes in sea level is causing damage to their taro fields and so it's a very much more direct impact than we tend to think about" (PSIS 804 ). The last respondent concurred with the others saying, "I would say that climate change is being addressed in a very sporadic manner" and that "it's mostly coming from nonprofits" on-island rather than from the island government $\left(\mathrm{PSIS}_{739}\right)$. In these cases, nonprofits refer to foundations, community groups, and religious organizations.

The second location had respondents stating that climate change is "I think beyond what's happening with the reefs and sea level rise" while the "majority of the residents here really don't understand [...] they automatically tie it into the reefs, and how it affects the reefs" $\left(\mathrm{PSIS}_{737}\right)$. This sentiment is echoed with another response discussing how the island has "been able to leverage a lot of funds for research, specifically relating to coral reefs and fisheries and climate" (PSIS $\left.{ }_{803}\right)$. An additional respondent said that they would like to "go to each village and create sea level rise maps and give it to them, here, look, look this is simulation. Now, I'm not saying that you're going to drown in 2 years or so, but for your children" you may want to make future plans (PSIS $\left.{ }_{602}\right)$. Lastly, it was stated that "I don't think there's much going on in the territory. And, I'm probably aware of climate change because I'm in the meetings $[. .$.$] however the community is not really engaged in any activities or whatever that$ other countries or territories are doing because I'm not sure if the whole territory is aware that climate change is a problem here" (PSIS 858$)$.

In the third location a respondent stated that "climate change is fairly new" on the island $\left(\right.$ PSIS $_{788}$ ), whereas another stated that they would want to "get a group together and talk about this issue and how we are going to address it for islands" (PSIS 978 ). The last two respondents wished to pinpoint "where maybe some of our more resilient ecosystems and reefs are" $\left(\mathrm{PSIS}_{627}\right)$, with the last stating that climate change "is probably something we haven't really discussed until maybe the last year and a half" (PSIS 678$)$.

\section{Interviewees' responses to Question \#2}

Question \#2 pursues a more in-depth look into how climate change is described in each of the islands. In the first location the respondent stated that there is "not lack of awareness that climate change is occurring globally, the issue is that it's not very clear what that change will mean for $[\star \star]$ in particular" $\left(\operatorname{PSIS}_{944}\right)$, with others saying that "people are quite honestly apathetic, I don't think it's on the radar" (PSIS $\left.{ }_{700}\right)$. Climate change is not a primary worry in the jurisdiction because "a lot of other things that are more immediate [...] and climate change is hard to get your hands around [...] such a long-term thing doesn't fit well with politics which people are trying to get reelected a lot" (PSIS $\left.{ }_{954}\right)$. When there is interest in preparing for climate change it is monetarily based as "people who are following the money and there's money for climate-change remediation, adaptation and so their people are saying of course yea $[\ldots]$ we need this money" (PSIS $\left.{ }_{920}\right)$.

In the second location the "general attitude in the government seems to be more along the lines of oh this is something we should worry about because everyone else is worried 
about it" $\left(\right.$ PSIS $\left._{892}\right)$, and another reinforces the newness of climate change by saying, "we just started doing the climate change as the, as a group of all government agencies, yea. So not a lot of people are aware of climate change, so that's why we're trying to educate" ( $\left.\mathrm{PSIS}_{853}\right)$. Others state that on-island they "definitely need to do a better job of doing public outreach. I wouldn't say there's a negative attitude, I would say there is just a lack of understanding" about what climate change is $\left(\mathrm{PSIS}_{719}\right)$, whereas most people acknowledge and try to understand it but they "don't have any ideas on what exactly it means for them and their lives going forward" (PSIS 575$)$.

In the third location, respondents state that because "this is a very religious area, and people just kind of say oh well, you know we just rely on the Lord to help us if anything and, but for me, I feel like the Lord helps those that help themselves, so, I am concerned" (PSIS ${ }_{705}$ ). Religion is mentioned again with respondents stating that the "general public needs also to be aware of it, so what I don't see and what I don't hear in the radio [...] in the media, in the schools, in the church groups, because that's one of the target audience here is the church groups" (PSIS $\left.{ }_{815}\right)$. The final respondent stated that regarding climate change, "I think people aren't as sure what to do about it, but they're convinced that it's going to be a problem" (PSIS 764 ).

\section{Interviewees' responses to Question \#6}

PSIS Question \#6, regarding the territorial statuses of the islands, asked what they think of their non-state, non-sovereign status with regard to climate change. In the first location the respondent lamented that it is "not only with climate change, but it's in everything else, we just get whatever the leftovers are [...] okay we'll give you this, we have some leftover stuff for you guys, sorry to say that, but that's just how it is" (PSIS ${ }_{904}$ ). That view is supported by another respondent stating that territorial status is "slightly detrimental" but it does make "us a little more independent as far as our climate-change preparations go. We're able to work with other territories [...] and we're able to work through [regional environmental organization] in certain ways," yet even with that advantage, within [regional environmental organization], "it's kind of a little challenging because it is we're kind of on the outside looking in" (PSIS $\left.{ }_{923}\right)$. This sentiment expresses the concern of territories not being able to fully participate in Pacific regional associations as participation is often reserved for independent countries, not semi- or partially autonomous islands. When the US Territories are able to participate in climate-change activities involving those outside of the territory, they "look at us like we got a lot of money [...] every time they look at us they feel like we got all this US dollars [...] It benefits us but it also creates hardship for us, because there are lot of areas where we're not similar to the States and their jurisdictions" (PSIS 641 ).

The reality of being an island and part of the United States hits home with this quotation:

I was representing the territory [...] And I said, oh, but nobody from the United States is here?, I am here, then we should be acknowledged as members of the US and they're like, oh no, because you guys would have to go through the US, the US people will speak to them [...] And then the way the other islands are treating $(\star \star)$ is like that, like okay we're not going to talk to you because the US, we have to have a representative from the United States. (PSIS 620 )

The second location, when asked about their sovereignty and status, responded that the "fact that there are some other Pacific Island states that are already having some pretty serious impacts from climate change has sort of, I think it's both helped and hurt a little bit our attempts" at trying to proactively plan (PSIS $\left.{ }_{703}\right)$. Similarly, another respondent stated that it "doesn't seem like our being part of the US [...] hampered our, our acceptance of climate change here. I think if anything we kind of embrace it more because we want to" (PSIS $\left.{ }_{767}\right)$. Interestingly, sometimes it is the new-fangled forms of governance that get in the way, as one 
responded stated that it is "just the conversation you have with how are you going to address this and in Palau they're like oh, the elders just said we're going to plant more taro, boom, done, everyone listens to it. Here it's like well, you can't'" (PSIS $\left.{ }_{834}\right)$.

Some of the additional difficulties with being a territory trying to plan for climate change while part of the United States is that some "think that it does and I'm trying to remember the example where we wanted to go to this meeting and we couldn't go [...] We're trying to get the Governor [...] they both were like reluctant to sign it because they said, I think we have to go through the US Department of State before we sign anything like this" ( $\left.\operatorname{PSIS}_{837}\right)$.

In the third location respondents spoke to the benefits of territorial status such as "because we're a US Territory they're going, if it's big huge disaster does come in [...] it will get taken care of by the United States" while acknowledging that there are "pros and cons with being a territory [...] one pro of being a territory of the United States but if like a terrible, horrible horrific emergency or disaster happened you do have the US which has a lot of financial support to kind of helping you out" (PSIS $\left.{ }_{962}\right)$. The next respondent stated that the US has "huge sources of government revue and this security that you have being a totally part of the US" benefits and allows the jurisdiction to proactively plan for climate change (PSIS ${ }_{591}$ ). Other respondents more cautiously stated that the relationship between territory and the US is "an understanding that our place in the Pacific [...] and our relationship with the United States, maybe we are the canary in the mine," and that through association issues surrounding climate change can be discussed. $\left(\mathrm{PSIS}_{959}\right)$. This outreach from the United States is already happening according to the last respondent saying that there are "more resources coming from the US government like sponsoring [...] more workshops" even though sometimes it is available to independent countries and or the territories whereas "other kinds of funding through [...] the European Union that won't come [...] but it will go to our neighboring countries" (PSIS 563 ).

\section{Interviewees' responses to Question \#8}

PSIS Question 8 attempts to evaluate features of the territories. In the first location the respondent stated that "we have more access I think to direct US funds, but we don't have access to international funds" (PSIS $\left.{ }_{855}\right)$, and is further supported by another respondent saying that territorial status is "a good thing and maybe a bad thing because good thing is that we're part of the US and we can get all this funding, bad thing is sometimes we want to be engaged more in these other networks and we can't because US Department of State" would have to do that and it happens very infrequently (PSIS ${ }_{618}$ ). This opinion is further solidified by a respondent in the jurisdiction stating that it is "definitely like a double-edged sword to where it helps [...] we get a lot of the funding opportunity to implement these programs and projects but the difficult part is we don't fit in with a lot of the plans or boxes that are being developed for like the states, and even Hawaii which may be the closest analog" ( $\left.\mathrm{PSIS}_{993}\right)$. The idea of a two-edged sword is further supported by the response stating that "it's bigger than just climate change, right $[. .$.$] Is it good to be attached to the US or not? Sometimes yes sometimes no" (PSIS 840$ ).

The second location spoke positively about being part of the greater network of the United States since it "is an asset having the United States [...] because you'll get a lot of help you get a lot of expertise to help guide" and without the United States' assistance that might not happen" (PSIS $\left.{ }_{955}\right)$. The next stated that "I think that we are at the best position we're at now [...] so if they're going to have a mandate on climate change, you're going to follow it, or you're not going to be funded for it" (PSIS ${ }_{856}$ ). Further supporting this opinion is the idea that it is "an asset in the availability to different resources, especially federal agencies bringing in people who have expertise in a lot of different areas" ( $\left.\mathrm{PSIS}_{759}\right)$. However, one respondent did express great frustration in that "it's a shame to be associated with one of the most powerful nations in the world, and just not have a national policy on climate change [...] we 
have about 12 federal agencies that sit in on the table. They agree on everything but having the word, term climate change on paper" (PSIS 864$)$.

In the third location respondents did say that the United States is an asset in "preparing for anything because especially to the extent of the preparation of all federal money," but at the same time "we perceive ourselves to be kind of second-class citizens in a lot of ways because we don't get, you don't have representative in Congress, but you get a delegate, but they don't vote" (PSIS $\left.{ }_{966}\right)$. Other examples say that theoretically the relationship is an asset but "in dealing with climate change, absolutely [...] I would envision the answer is yes, but what I've seen so far is no" (PSIS $\left.{ }_{805}\right)$.

Additional respondents stated that it is an asset, but simultaneously small islands are "the most impacted by what everyone else in the world does. And I don't think combined we get enough funding whether internationally or from the United States to somehow reduce the impacts that it's causing on our island states" (PSIS 604$)$. Lastly, the final respondent states that "it's a trade-off [...] it's a strength in that we [...] have access to certain programs that we wouldn't have access to [...] we get a lot more benefit from being part of the US than we lose" $\left(\mathrm{PSIS}_{583}\right)$.

\section{Results and discussion}

The first question (\#1) asked respondents to describe climate change on-island. Overall, climate change is viewed as a newer topic focused on reef and marine issues. Barriers to education, a vague interest and awareness by locals, and a feeling of being behind neighbouring islands is suggestive of insularity with minimal linkages to the United States (Taglioni, 2011). A hyperinsular relationship is present insofar that isolation to federal climate policy exists within the islands as it is the norm although not necessarily sought-after (Taglioni, 2011, p. 56). Responses varied, but often had environmental and coral reef-based perspectives speaking to the "imagined territories" or "imagined regions" questions discussed in regional governance, as if climate change in this territory did not really have much effect on humans, excluding issues related to coral reefs (Balsiger \& Debarbieux, 2011, p. 3).

Other ways in which climate change was addressed included a focus on resilience through community education, although it was stated that the educational aspect is still within its infancy. Thus, if policy is not coming from the federal level it is unlikely that a bottomup approach "whereby two or more states join common cause" to initiate climate-related policy will spring forth from the territories (Rabe, 2008, p. 124) Respondents discussed the newness of climate-change discussions and programs on-island. Once more, coral reefs and biologically related activities were highlighted, but there was a prevalence of infrastructure protection or relocation mentioned by several respondents. Ironically, the idea of "sovereign peoples with innate rights to territory" is firmly rooted in the subject matter; yet, on territorial outposts, they often lack both sovereignty and innate rights to the mainland country as citizenship is a bit complicated if any of the residents of this study's islands wished to relocate to the mainland United States (McNamara \& Gibson, 2009, p. 476).

The second question (\#2) asked about the general attitude of climate change on-island. There exists the indication that climate-change education, advocacy, and discussion are in nascent stages. There was also the idea that communities notice changes in precipitation or erosion and sometimes attribute these changes to climate change, but the term 'climate change' becomes a catchall for any environmental anomaly and little education goes towards educating residents, visitors, or tourists (Becken, 2005, p. 391).

Islanders spoke to the uncertainty regarding how to approach climate-change issues where they may be a priority of sorts, but other issues supersede climate change on the list of priorities. In addition, questions about incoming migration from the region, not understanding how to adapt to a changing climate, and looking to climate change as a source 
of money for the island were topics brought up by interviewees, which could cause disagreement on a unified trajectory (Julca \& Paddison, 2010; Ostrom, 1990). On-island interviews described the general attitude toward climate change as being something new and decision-makers were unclear how to educate residents. Slowly, portions of the government are taking the lead along with nongovernmental groups, but the momentum is slow. The general attitude toward climate change on-island was that it is just starting and is not affected by denial seen on the mainland. Respondents say it is somewhat affected by the religious population on island where planning for tragedies was either an invitation for calamities to happen or were going against an intended destiny designed by a higher power. Although there is a concern on this island that people do not know as much as they could or should, they may believe the future is in the hands of a higher being, or that until they see the effects firsthand, it is not something to worry about. If some of the barriers to working alongside neighbouring PSIS that are not US Territories were taken down then common pool resources could doubly serve to successfully manage and invite management of resources to reduce the hesitancy in planning for climate change (Martin, 2010).

A common response stated that there were more pressing items, such as the economy, that surpass climate change as important topics for the public and elected decision-makers, who are without regard for or do not notice the intrinsic "global applicability" between the economy and climate change (Mycoo \& Gobin, 2013, p. 449). There is not reluctance to adapting so much as there is confusion about how and what the foreseen impacts of climate change are locally. A lack of understanding of what climate change is, as differentiated from other environmental factors, is causing residents and decision-makers to falter with meaningful action and preparation. Items such as the constraints of regional migration and lack of currently observed localized effects of climate change all affect the attitude toward climate change in the PSIS of the American Territories in the Pacific-a twist on the environmental decision-making spoken about by Grote since the US mainland controls migration decisions (Grote, 2010).

In the third question (\#6), islanders were asked if their status as a US Territory alongside other non-territories affects climate-change preparation. Respondents echoed that yes, the territory's status in the region affects regional cooperation in terms of how climate change occurs. Almost all interviewees said that although there are some positive points about being part of the United States (as well as mentioning their patriotism and happiness about being part of the United States), there are many prohibitions and logistical bureaucratic processes associated with being a territory, creating a difficult environment in which to work collectively with other PSIS-explicitly discussed by Lipschutz and Conca when portending sound development policies (Lipschutz \& Conca, 1993).

Respondents often answered that being a territory of the United States hampers cooperation with other PSIS, although a fair number of respondents believed it did not greatly impede coordination. Some interviewees acknowledged that they were lucky to be living on $(\star \star)$ versus some of the independent PSIS that are more prone to feeling the effects of climate change today due to a twist of insularity (Taglioni, 2011).

Other respondents stated that territorial status does not affect the situation, and even when it does, it is a good thing. The examples most often given by interviewees were that being part of a larger country is the beneficial power exerted by the mother country via money and resources and power, as well as a sense of assurance in case of natural disasters (Hawksley, 2009). This viewpoint is introspective because it looks at what the islands accomplish as part of their association with the United States and the by-product of resilience. An alternate opinion on the matter is that the American Territories are full of firsthand knowledge and frustration, with interviewees voicing the obstacles that have stopped them from participating in climate-change preparation because they are territories among a sea of 
independent PSIS - the opposite of the argument and best practices offered by regionalization and cooperation (Grote, 2010).

Although territories are often invited to regional meetings on climate change, they have to sit out of the decision-making arenas because only Department of State personnel are at the decision-making level of their island peers. However, the Department of State rarely sends a representative. If it does, that person is often from Washington or New York, without much knowledge regarding Pacific territories, creating confusion and non-movement as sovereign states, with decision-making powers having trouble enough advancing sensitive topics forward on legal issues relating to the effects of climate change (McAdam, 2010). Thus, there is a spectrum of two dialogues surrounding American Samoa, Guam, and the Commonwealth of the Northern Mariana Islands: one in which their status as territories is detrimental to selffulfilling and forward-thinking planning and another where they are supposedly provided for by a large power, providing a guarantee of assistance that interviewees stated other PSIS would be jealous to have in the event of a disaster or natural phenomena. Both options are powerful and could be used as guidance toward creating stronger, more resilient climate-change planning tools in the future for the American Territories in the Pacific.

The final question (\#8) was similar to the previous one, yet outright asked if being part of the US was an asset in climate-change preparation. Respondents stated that yes, being aligned and supported by the United States was undoubtedly an asset to climate-change preparation. But, there was a vocal minority among the interviewees who maintained that there is a balance between the positive and negative effects-which are often associated with the relationship between a territory and host country. Interestingly, several respondents actually said that if there were any shortcomings, it was more likely to be a lack of initiative and progress on-island versus a lack of United States-based policy. However, some stated that the relationship is simultaneously helpful and hurtful to advancing climate-change-adaptation planning. In almost all the cases in which respondents said that it was helpful, that helpfulness focused on funding, research, and availability of experts from the mainland.

Respondents' answers addressed how the American Territories in the Pacific reacted to the question of whether being part of the United States was an asset-or not - in preparing for climate change. The island jurisdictions believed that funding was paramount for preparing for climate change, but there needs to be a bit more accessibility and integration with the region. At the same time, it was noted that this is not the only area in which the relationship between the territories and their neighbours create a grey area in cooperation-something that changes depending on what type of leadership is at the helm (Jacobs, 2005). From these interviewees' statements and quotations, the next step in climate-change preparation would be alleviating the difficulties, inconsistencies, and roadblocks hampering the otherwise beneficial relationship that the island territories have with the United States. For example, the US Department of State should reach out to the islands to better understand their viewpoints and the obstacles they face when they cooperate with neighbours so that islanders can speak for themselves or have an available State Department representative, such as a designated liaison from Washington who is familiar with islanders' culture and points of view.

The interviewees' responses at the American territorial level helped uncover some of the mysteries of climate-change adaptation success and failures within regional cooperation or its nonexistence. First, PSIS and their residents need an understanding of climate change and the plans to address these impacts. Although some communities have achieved this, it is lacking in many communities. Fixing this problem would aid in localizing both the perceptions and understanding of impacts and strategies to better adapt. Most policies in place are focused on coral reefs and marine systems, which should be a focus, but not the sole focus. These policies are likely a vestige from the days when both a definition and ability to talk freely about climate change led to lackluster policies when robust ones were needed. Regional linkages in the territories are found in three components: the American Samoa and Samoa 
Cohesive Initiative; the Micronesian affinity among Guam, the Commonwealth of the Northern Mariana Islands, and the surrounding states of the Marshall Islands, Federated States of Micronesia, and Palau; and, Honolulu as an administrative hub for much of the Pacific and corresponding American territories.

The question of how to better coordinate within the region was hindered both by governments in the territorial governments choosing which associations they want to participate in (with varying rates of acceptance), contrasted with the independent PSIS that belong to most, if not all: United Nations negotiations, fishing policies, sub-regional cooperation, Pacific Islanders networks, and the like. Territorial CCAPs are nearly impossible to find on any government website, whereas the 50 states are coordinated in their administration to have certain reports easily disseminated through their websites. Similar to the American Territories, it is sometimes difficult to find sovereign states' CCAPs on their particular websites. Nonetheless, the relationship with the United States is overwhelmingly viewed as an asset to residents in American Samoa, Guam, and the Commonwealth of the Northern Mariana Islands, but environmental protocols, enforcement, and liaising restrictions need renovation.

Interestingly, the self-articulated island resilience from interviewees is perceived as high within the American territories in the Pacific because of past natural disasters, war, military bases, and past hazard preparations not falling under the umbrella of climate-change adaptation or preparation and is often referred to as disaster and risk reduction policy. The geographical and historical aspects of islands-such as high island types-do affect the local contexts of the islands. Surprisingly, islanders did not readily point out any key physical characteristics of their islands as making them more resilient than neighbours. They also did not regularly point out differences in governance and territorial status with the United States versus the technical territorial or commonwealth status. While there is a cultural and geographical similarity to other PSIS, the territories in this study lack urgency in preparing for climate change while other PSIS more urgently prepare (see Schwebel, 2018a). The three territories all referred to inherent resilience on-island, such as topography and height, assumed assistance of the US Government based on prior examples, and upward mobility within the region and US. There were, of course, concerns mentioned throughout this manuscript, but they mostly addressed a far-off and hypothetical disaster. Finally, a greater understanding of climate-change predictions, better outreach, and community education can lead to better adaptation strategies.

\section{Conclusion}

This study validates that climate analyses and policies in American Samoa, Guam, and the Commonwealth of the Northern Mariana Islands were located at the periphery of analyses and implementation as prior studies illustrate how independent states are the principal focus in climate-change planning and adaptation (Weir \& Pittock, 2017). The situation is, indeed, complex when dealing with how the United States Territories work with each other and their neighbours. While previous research has looked at potential climate-change adaptation 'success' in anticipating and planning for the forecasted effects of a changing climate via plans and legislation (see Robinson, 2017; Schwebel, 2018b) there is no alternative to dealing with the unilateral sovereignty- the United States-in charge.

It is unlikely that either a PSIS or a territory would withdraw itself from the rules that are imposed on their actions or behaviours from their host country, because it would change the very essence of the individual, in addition to causing all forms of other difficulties. Yet, as was just recently observed in the other two inhabited United States territories-Puerto Rico and the US Virgin Islands-responses to high-profile disasters such as Hurricane Maria in 2017 illustrate the extant vulnerabilities currently in place and the difficulties with getting 
assistance to islands, which could add frustration to societies that heavily rely on a (false) sense of assurance from their host country.

Lastly, while some respondents were visibly and audibly frustrated by the lack of planning, understanding, ability to work with neighbours, and an overall lack of momentum of climate-change planning within the United States Territories in the Pacific, surprisingly there was not an overall sense of urgency from the majority of respondents. Only time will tell if there is, indeed, built-in resilience afoot in the territories or if the future brings to the shores of American Samoa, Guam, and The Commonwealth of the Northern Mariana Islands the very type of events for which many of their sovereign neighbours are currently preparing.

\section{References}

Balsiger, J., \& Debarbieux, B. (2011). Major challenges in regional environmental governance research and practice. Procedia Social and Behavioral Sciences, 14, 1-8. https://doi.org/10.1016/j.sbspro.2011.03.010

Becken, S. (2005). Harmonising climate change adaptation and mitigation: the case of tourist resorts in Fiji. Global Environmental Change, 15(4), 381-393. https://doi.org/10.1016/j.gloenvcha.2005.08.001

Bedford, R. (2008). Migration policies, practices and cooperation mechanisms in the Pacific. Bangkok: United Nations Economic and Social Commission for Asia and the Pacific.

Bernard, H.R. (1988). Research methods in cultural anthropology. Lanham, MD: AltaMira.

Bernauer, T. (2002). Explaining success and failure in international river management. Aquatic Sciences, 64, 1-19. https://doi.org/10.1007/s00027-002-8050-4

Betzold, C. (2010). 'Borrowing' power to influence international negotiations: AOSIS in the climate change regime, 1990-1997. Politics, 30(3), 131-148. https://doi.org/10.1111/j.1467-9256.2010.01377.x

Biermann, F. (2004). Global environmental governance conceptualization and examples (Working Paper) (No. 12). Amsterdam: Global Governance Project.

Chasek, P.S., Downie, D.L., \& Brown, J.W. (2010). Global environmental politics. Boulder: Westview.

Docherty, B., \& Giannini, T. (2009). Confronting a rising tide: a proposal for a convention on climate change refugees. Harvard Environmental Law Review, 33, 1-62.

Grote, J. (2010). The changing tides of small island states discourse: a historical overview of the appearance of small island states in the international arena. Verfassung Und Recht in Ubersee, 43(3), 164-191. https://doi.org/10.5771/0506-7286-2010-2-164

Hawksley, C. (2009). Australia's aid diplomacy and the Pacific islands: change and continuity in middle power foreign policy. Oxford: Taylor \& Francis.

Jacobs, R.E. (2005). Treading deep waters: substantive law issues in Tuvalu's threat to sue the United States in the International Court of Justice. Pacific Rim Law \& Policy Journal Association, 24(52), 103-128.

Jarratt, D.G. (1996). A comparison of two alternative interviewing techniques used within an integrated research design: a case study in outshopping using semi-structured and nondirected interviewing techniques. Journal of Marketing Practice: Applied Marketing Science, 14(6), 6-15. https://doi.org/10.1108/02634509610131108

Julca, A., \& Paddison, O. (2010). Vulnerabilities and migration in small island developing states in the context of climate change. Natural Hazards, 55(3), 717-728. https://doi.org/10.1007/s11069-009-9384-1

Kelman, I. (2014). No change from climate change: vulnerability and small island developing states. The Geographical Journal, 180(2), 120-129. https://doi.org/10.1111/geoj.12019

Lipschutz, R.D., \& Conca, K. (1993). The state and social power in global environmental politics. New York: Columbia University Press. 
Martin, S. (2010). Climate change, migration, and governance. Global Governance, 16(3), 397414.

McAdam, J. (2010). 'Disappearing states', statelessness and the boundaries of international law. University of New South Wales Law Research Paper No. 2010-2.

McNamara, K.E., \& Gibson, C. (2009). "We do not want to leave our land": Pacific ambassadors at the United Nations resist the category of 'climate refugees'. Geoforum, 40(3), 475-483. https://doi.org/10.1016/j.geoforum.2009.03.006

Mycoo, M.A., \& Gobin, J.F. (2013). Coastal management, climate change adaptation and sustainability in small coastal communities: leatherback turtles and beach loss. Sustainability Science, 8(3), 441-453. https://doi.org/10.1007/s11625-013-0212-x

Ostrom, E. (1990). Governing the commons: the evolution of institutions for collective action. New York: Cambridge University Press. https://doi.org/10.1017/CBO9780511807763

Page, E. (2008). Distributing the burdens of climate change. Environmental Politics, 17(4), 556575. https://doi.org/10.1080/09644010802193419

Rabe, B. (2008). States on steroids: the intergovernmental odyssey of American climate policy. Review of Policy Research 25(2), 105-128. https://doi.org/10.1111/j.15411338.2007.00314.x

Robinson, S.-A. (2015). Climate change adaptation trends in small island developing states. Mitigation and Adaptation Strategies for Global Change, 22(4), 669-691. https://doi.org/10.1007/s11027-015-9693-5

Schofield, C. (2009). Shifting limits? Sea level rise and options to secure maritime jurisdictional claims. Carbon and Climate Law Review, 3(4), 405-416. https://doi.org/10.21552/CCLR/2009/4/111

Schwebel, M. (2018a). Gathering at the AOSIS: Perceived cooperation amongst Pacific small island states. Journal of International Environmental Agreements, 18(2), 215-228. https://doi.org/10.1007/s10784-017-9379-4

Schwebel, M. (2018b). Measuring climate change adaptation in Pacific small island states: nissology and success. Journal of Water and Climate Change, 9(1), 112-123. https://doi.org/10.2166/wcc.2017.019

Selter, J. (2015) Testing the boundaries of subnational diplomacy: the international climate action of local and regional governments. Transnational Environmental Law, 4(2) 319337. https://doi.org/10.1017/S2047102515000126

Taglioni, F. (2011). Insularity, political status and small insular spaces. Shima, 5(2), 45-67.

Tompkins, E.L., Nicholson-Cole, S. A., Hurlston, L.-A., Boyd, E., Hodge, G.B, Clarke, J., Gray, G., Trotz, N., \& Varlack, L. (2005). Surviving climate change in small islands: a guidebook. Norwich: Tyndale Centre for Climate Change Research.

Ware, H. (2005). Demography, migration and conflict in the Pacific. Journal of Peace Research, 42(4), 435-454. https://doi.org/10.1177/0022343305054090

Weir, T., \& Pittock, J. (2017). Human dimensions of environmental change in small island developing states: some common themes. Regional Environmental Change, 17(4), 949958. https://doi.org/10.1007/s10113-017-1135-3 